\title{
Racism and Stereotypes
}

\author{
Paul Spoonley
}

\section{Contents}

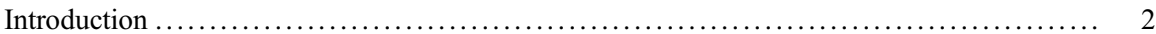

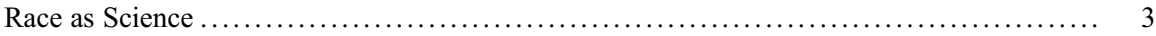

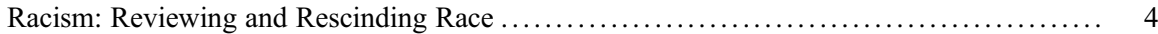

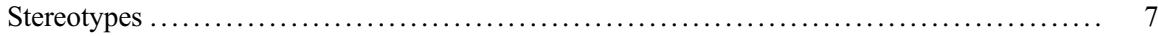

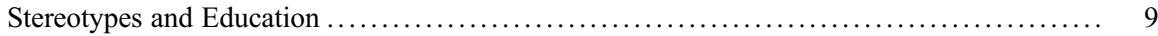

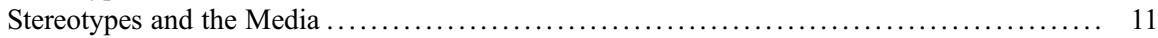

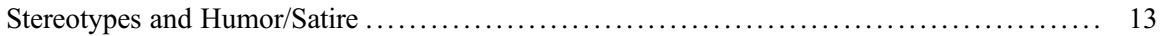

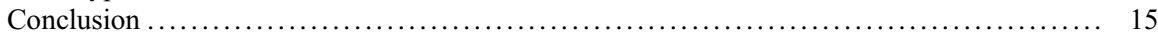

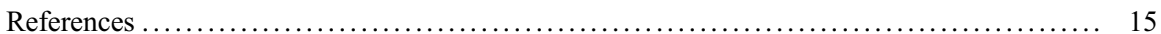

\begin{abstract}
One of the major shifts in scholarship in the twentieth century was to move away from a reliance on the science and popular understanding of "race" to a more critical and nuanced approach that included a focus on ethnic identity and a vocabulary that included racism. These shifts prompted the race-inspired genocide of the Holocaust combined with the growing decolonization politics of the colonized, both those that were colonized as part of a process of occupation and settlement or those that were excluded and marginalized as a result of the racism of hegemonic communities or institutions of those states. The decolonization politics of the mid-twentieth century included those residents in metropolitan economies and societies as a result of what was often a process of forced migration. The struggle for recognition and equity also included those that had existed as preexisting nations within colonies but were now subjugated peoples.
\end{abstract}

P. Spoonley $(\varangle)$

College of Humanities and Social Sciences, Massey University, Auckland, New Zealand e-mail: P.Spoonley@massey.ac.nz 
One of the most important components to these politics of colonization and ongoing marginalization were the presence of stereotypes, the attribution of certain characteristics, typically negative in tone or content, to a whole group of people. As racism has changed in the late twentieth century and through the first decades of the twenty-first century, some stereotypes have remained constant while others have changed or new ones emerged. These stereotypes are invoked and reproduced in a range of settings, including institutions such as the media (new as well as traditional or education, or as an aspect of social commentary and exchange, such as comedy and humor) and as part of humor.

\section{Keywords}

Race $\cdot$ Racism $\cdot$ Stereotypes

\section{Introduction}

An explanation of phenotypical, cultural, and intellectual differences was embodied in the notion of "race" that was part of a (long) period of European expansion and colonization. Popular understanding of what constituted race was underpinned by the "science" of race, including as a justification for exploitation and colonization. These world views were contested by a growing opposition to slavery from the late 1700 s, but it was the deployment of arguments about race and the use of these to justify genocide in Europe during World War II that prompted a significant shift: to critique arguments about race and to acknowledge cultural identity (ethnicity) as an alternative.

This period, dating from the late 1940s, paralleled a period in which decolonization politics were more forcefully articulated as subjugated peoples and nations fought for recognition and to contest cultural and economic marginalization. The civil rights movement added another dimension to these politics of resistance. A more critical science of difference and inequality emerged, and common to both, the movements of resistance and social science was a concern with the presence and impacts of racism. There was an interest in the process by which particular categories/groups of people became racialized (defined and problematized as a "race").

One of the key elements in the product and reproduction of racism is the presence and utilization of stereotypes. Essentially, these are the attribution of characteristics, in a simplistic way, to a group that has been racialized. This attribution or categorization of others is typically couched in negative or hostile terms, and these stereotypes sustain derogatory views of others - and to justify, discrimination and various forms of exclusion. This chapter explores the nature of these stereotypes and uses two institutional settings - the media and education - to explore the nature and impacts of stereotypes and ends with a discussion of comedy and humor. Stereotypes are widely used in such settings and what is - or is not -acceptable is an interesting test of public sentiment and analyses of racism.

Stereotypes remain an important part of the vocabulary and practice of racism. In one sense, they can be relatively innocuous and simply part of the way in which 
humans understand and explain their social world in a banal and mildly problematic way. But this characterization tends to undermine their ongoing contribution to popular and political racism, to ignore the impact on those being stereotyped and to resist the perniciousness of contemporary racism.

\section{Race as Science}

While the idea of "race" is now seen as problematic, at least in academic circles, during a period of European expansion and underpinned by scientists and science of the period, race was a key concept in both explaining phenotypical difference and in justifying the attitudes and actions towards others, essentially the non-European "other" (including Jews). The explorations and expansionism of Europeans from the 1600 s onwards brought those explorers and then subsequently colonizers/settlers into contact with people who were physically and culturally different. Race became a core concept in explaining these differences and the "superiority" of the European colonizers and the "inferiority" of those encountered (and therefore their rights to subjugate and enslave). The developing biological sciences helped in this process by providing a scientific justification for these beliefs. The mid-nineteenth century development of eugenics is one of many examples of racial classification and the development of the science of measuring racial difference, and ultimately, resulting in the differential treatment of races. A second element was the appearance of social and economic systems such as slavery which required the absolute subjugation of certain peoples. As the opposition grew to systems such as slavery from the late $1700 \mathrm{~s}$, justifications were sought to preserve an economic and social system that depended on the subjugation and exploitation of others. The science of race and the beliefs of elites and hegemonic communities reinforced the key elements in race: that groups could be classified in terms of their phenotypical differences; and that these phenotypical differences reflected innate characteristics between races; that races could be ordered into hierarchies based on how differences in terms of intellect or competence were differentially allocated amongst races according to those doing the allocation (Banton 1978; Miles 1989). Underpinning these beliefs, both scientific and popular, were stereotypes (which will be explained in more detail below) about the perceived nature and key characteristics of groups who were being racialized.

A key moment in relation to the science of racism and the use of race to categorize and justify exclusion and subjugation came in the mid-twentieth century as the full realization of the Holocaust was made clear. The fact that a "modern, advanced" state, in this case Germany, could utilize beliefs about the "superiority" of Aryans and "inferiority" of many others, but especially the Untermenschen - Jews and Romany in particular - in order to justify genocide invited many to revisit beliefs in race. After the end of World War II, international agencies lead a debate about the nature and consequences of beliefs in race. Probably the most significant came from UNESCO who sponsored a series of expert panel meetings in the 1950s and 1960s. A statement noted that race is essentially an arbitrary social classification that then gained a dubious science to underpin these social beliefs. The preexisting science of 
race and the Holocaust were based on a "scientifically untenable premise" (Miles 1989: 46). The issue of deciding who is or is not a member of a particular race is problematic and relies on social conventions and beliefs - and characterizations of phenotypical difference. There is now a substantial literature which discounts race as a scientific concept (UNESCO 1975; Banton 1978) and which points to the ideological and political content of the term - and the very destructive consequences of these beliefs.

\section{Racism: Reviewing and Rescinding Race}

While there had been concerns expressed about both the scientific validity of race and the way in which it was used to denigrate and exploit since the late 1700s and through the 1800s (see Quaker campaigns against slavery), and some of those who were on the receiving end of racism resisted subjugation and denigration in various ways, international understanding and skepticism was muted. For example, the allied countries and their leaders did not accept the stories about Jewish and Romany genocide until the evidence of the death and concentration camps at the end of the war forced a re-evaluation. Through the late 1940s through to the 1970s, scientific communities began to unpack and critique the science of race and populist beliefs about race. This was accompanied by the decolonizing politics of the colonized (cf Fanon 1967; Freire 1968) and the civil rights movement.

Racism, as an increasingly widely used term, was used to signal the presence of ideological beliefs that people can be classified into races and that these racial differences explain physical/intellectual differences and the outcomes of social variation (Miles 1989). In this sense, racism refers to the beliefs about racial difference and typically that these differences signal innate characteristics which translate into hierarchies of superiority and inferiority. It includes a "mix of prejudice, power, ideology, stereotypes, domination, disparities and/or unequal treatment" (Berman and Paradies 2010: 228). In the latter half of the twentieth century, as part of a varied set of decolonizing politics, the connection of racism with colonization and power differentials became an important part of academic and public discourse - and of resistance. Commentators such as Fanon (1967) and Freire (1968) provided a powerful critique of colonialism and what was required to decolonize. Civil rights and Black activists in the United States added to this element, notably in the introduction of concepts such as institutional racism in the late 1960s. This notion, institutional racism, supplemented the existing focus on personal prejudice and the impacts of racism on those targeted and began to stress the structural components and outcomes of racism. Institutional racism "refers to the ways in which groups are differentially treated by institutions as a result of a set of organizational policies and procedures" (Spoonley 1995: 21) whereby certain discriminatory practices are normalized and routinized within the organization (cf Downing and Husband 2005). The institutions referred to typically those that are at the core of states and the allocation of goods, status, and services - education, justice, welfare, housing, employment - and the assumption is that the behaviors of individuals who occupy 
positions in those institutions are less significant than the way in which the institution operates to disadvantage particular racial groups. This might involve differential access, or limited access, to resources and services and the emphasis on the norms and expectations of hegemonic ethnic groups to the detriment of indigenous or minority ethnic groups, with the result that life chances and outcomes vary considerably depending on the ethnic group in question. One of the interesting arguments in relation to institutional racism is that those in the institutions might not be racist themselves but that the key factor was that the institution in question contributed to inequity by operating in a racially advantageous or disadvantageous way.

Through the $1970 \mathrm{~s}$, the emphasis on racism being a combination of prejudice plus power, and an increasing focus on the structural impacts of racism, guided understanding of racism. And these politics and emphasis began to be seen more widely in academic understanding. For example, Rex and Moore (1967) wrote about housing classes in the UK, to signal the way in which the housing market was determined by racial exclusion. But perhaps the more important shift came in the 1980s when writers like Robert Miles and Stephen Castles linked migration and racism to neoMarxist arguments about structural disadvantage. A classical Marxism, they argued, was inadequate because of its exclusion of ethnic dynamics in contemporary (or historic) capitalism and the reductionism of economic inequity to class. Miles (1982) argued for the political economy of labor migration which argued that the underlying driver of capitalism was capital accumulation and the need to find more profitable ways of producing and exchanging goods. In post-war capitalist economies, one strategy was to recruit workers from the periphery, often former colonies of the urban-industrial centers of capitalist production. But as Miles went on to point out, not only were these workers a source of waged labor, they brought a different culture and were defined as races that were often problematized. Political and ideological relations were altered as contact and exchange took place in the metropolitan centers of capitalism. In Miles' (1982) terms, relationships between these different groups were "racialized." The migrants are defined as physically and culturally different, that is as "races" that drew upon preexisting notions of inferiority and superiority of these socially constructed races. Moreover, these racialized migrants and their presence were seen as problematic in terms of issues such as contributing to the decline of urban areas, law and order and as a cultural threat. And the class structures and advantage/disadvantage of capitalism was now significantly structured by these racialized relationships, so that the groups racialized were excluded or marginalized in significant ways. Castles et al. (1984) added to this approach, and it was underscored by contributions such as Paul Gilroy's (1987) There Ain't No Black in the Union Jack and the attention paid to forms of resistance by those colonized or racialized.

Miles (1982), influenced by Fanon (1967), referred to racialization, or the way in which "relations between people have been structured by the signification of human biological characteristics in such a way as to define and construct differentiated social collectivities" (Miles 1982: 75; see also Murji and Solomos 2005). This, in Fleras's (2014: 73) terms, reflected an important conceptual shift with a focus on the "process of defining, categorizing, and evaluating people and their activities along 
racial lines" with the emphasis on the ideological underpinnings (including the deployment of stereotypes) and category construction. In this way, defined groups are constructed by a process of attributing racial significance and problematized in various ways. The significance of this shift is to underline the process of social construction using (largely) negative perceptions and characterizations, and thereby rejecting any suggestion that racism is a "natural outcome of intergroup contact" (Fleras 2014: 74). The social construction of these world views rely on categories and stereotypes, what Goldberg (1993) refers to as "preconceptual primitive terms" that simplify and explain as part of the logic of racism.

These evolving approaches to racism were reflected - and influenced by activists and writers from those colonized. For example, in New Zealand, these ideas (from Fanon through to more contemporary neo-Marxist approaches) were influential in contributions from the indigenous and subjugated Māori and can be seen in statements such as Donna Awatere's (1984) Mãori Sovereignty which provided an interesting analysis of racism and the idea that the sovereignty of the modern state, in this case in New Zealand, could be renegotiated to ensure that indigenous peoples, Māori, could exercise their own (albeit partial) sovereignty. An indigenous scholar, Ranginui Walker (1990), provided a powerful critique in his book, Ka Whawhai Tonu Matou. Struggle Without End, in which he linked colonial dispossession and racism with contemporary (highly negative) outcomes for Māori, and argued that both personal and structural racism needed to be confronted. Such approaches continue to remain influential in relation to contemporary understandings of racism in Aotearoa/New Zealand (see, for example, Moewaka Barnes et al. 2013) so that structural racism (in Moewaka Barnes et al. 2013) is seen as being central to both societal and institutional racism with impacts for individuals and groups (notably Māori) in terms of detrimental health outcomes.

The use of the term racism, the process of racializing particular groups, and the critique of institutional racism were central to academic and popular understanding by the second half of the twentieth century. This was accompanied by the recognition that racism could and did take a variety of forms. For example, Fleras and Elliot (1996: 71-83) describe the variety of forms that racism takes, from the everyday and polite versions to more structural and institutionalized forms, and that the targets of racism and the perpetuators of it may equally take a variety of forms. They go on to argue that at its essence, racism is a powerful form of social control whatever its ideological underpinnings, content, or the way in which it is expressed and practiced.

... racism has played and continues to play a formidable role in establishing and maintaining patterns of inequality and control. (Fleras and Elliot 1996: 87)

If racism is now seen in a more nuanced way, it is also true that the extensive scholarship and interest provides some challenges. The term itself, racism, has a variety of definitions and is "seldom defined with any precision or consistency" and it is important to recognize that the term refers to a range of attitudes and behaviors (cf Fleras 2014) to a wide spectrum of contexts (Miles 1989 argued that the nature of 
racism was a product of particular contexts and historical trajectories). It is one of the enduring areas of scholarship and of political activism, and as the politics of the USA, or Hungary, or the UK in recent decades remind us, there is still significant currency in negative beliefs and actions directed at a visible or despised other. Despite an extensive literature, ample evidence, and resistance from those who are targeted by racism, beliefs about racial difference and threat can still be mobilized by nationalist and populist leaders. Despite the political and moral power of a description that some person or action is racist, beliefs about race and behavior based on those beliefs remain a potent and deployed explanation for certain constituencies (see Hochschild 2016).

Integral to racism are certain categorizations and beliefs - and central to these are the presence of stereotypes. What follows is a discussion on the nature of stereotypes and how they operate in certain institutional settings.

\section{Stereotypes}

Hurwitz et al. (1997: 31) define stereotypes as "cognitive structures that contain the perceiver's knowledge, beliefs, and expectations about human groups." But this is missing the evaluative or judgmental component in relation to racial categorizations and beliefs. The attribution of characteristics normally embodies a normative component and the attributed characteristics are either negative or positive depending on the group in question (cf Jewell 1993). It might be that stereotypes are neutral or even reflect positive views of others (see Downing and Husband's 2005: 33 discussions of "white stereotypes of Whiteness"). But stereotypes, especially as an underlying component of racism, embody simplistic, negative categorizations of a racialized other. They are categorizations that are "commonly infused with attitudes of hostility and hatred towards the group in question" (Giddens 1993: 256), thereby underpinning the racism with which such stereotypes are associated. As Fleras and Elliot (1996: 68) note, "stereotyping reflects a universal tendency to reduce a complex phenomena to simple (istic) explanations that are generalized to a wider category without acknowledging individual differences." As they go on to argue, these uni-dimensional images can be employed to justify "daily violence or structural oppression" and are an extension of social control" (Fleras and Elliot 1996: 69).

There are different disciplinary approaches to an understanding of stereotypes. For psychologists, there is an interest in cognition and the way in which racism is constructed and practised at the individual and/or contextual level (Fiske 2000). In responding to the question, "how have social psychologists approached this patchwork quilt of categorical thoughts, feelings, and behaviour?" (Fiske 2000: 299) in reference to stereotypes and prejudice, she notes that there are three major approaches to prejudice in relation to intra-individual dynamics that derive from earlier studies by contributors such as Adorno et al. (1950): 
(1) Modern or symbolic racism... focuses on policy beliefs that all happen to disadvantage minorities...

(2) ... ambivalent racism ... notes the tension between 'pro'-black attitudes (paternalistic pity for the disadvantaged) and 'anti'-black attitudes (hostility towards the oppositional deviant)...

(3)... aversive racism focusses on the tension between not wanting to be racist and simultaneous, unconscious cognitions that reflect racism. (Fiske 2000: 301)

All involve stereotyping in some form. The alternative approach, according to Fiske, derives from contextual analyses originating with writers such as Tajfel and Turner (see Tajfel and Turner 1986; Turner 1987). This is normally categorized as social identity theory (SIT) and centers on the argument that "people identify with and value their ingroup, thereby derogating the outgroup...[with] both cognitive (categorization) and motivational (self-esteem) foundations" (Fiske 2000: 303), so that there is a tendency to "accentuate differences between categories and minimize differences within categories" (Fiske 2000: 304). It is this tendency towards homogenizing categorized groups that underpins and reinforces stereotypes and "categoryconfirming information" is privileged (Fiske 2000: 304). Therefore:

People using strong stereotypes neglect ambiguous or neutral information...and assimilate others to the stereotype... [and] people seem to prefer stereotype-matching information. . . and may ask stereotype-matching questions. . . [and people privilege stereotype information. (Fiske 2000: 307)

Sociologists and others have often taken their lead from psychologists, notably in the connection between attitudes (prejudice) and negative categorizations (stereotypes). For examples, Macionis and Plummer (1998: 329) define stereotype as a "prejudicial, exaggerated description of some category of people." Here the connection to attitudes and prejudice is explicit. Other sociologists, such as Fleras and Elliot (1996: 68-69) stress the connection between stereotypes and ethnocentrism are "context and consequence" dependent. The interest here is on the presence of stereotypes in institutional practices, such as the media or popular culture (such as ethnic jokes). And the emphasis is on the role that stereotypes play in social control (Fleras 1998: 69). There is still an interest in the role that stereotypes place in prejudicial attitudes but also a strong connection to behavior whether in relation to discriminatory acts or institutional racism. There is some interesting analysis of the role of stereotypes in the practices of employers (McDowell 2008: 59), the visibility/ invisibility/hypervisibility of individuals and groups as central to stereotypes (Nagel and Staeheli 2008: 85-87), or victimization stereotypes of Asian women (male controlled, subject to arranged marriages; see Anthias and Yuval-Davis 1992: 125).

One way to test the relationship between stereotypes and the way in which race is refracted by communities is to look at how major public events or disputes are seen through a race lens. Those who take the Implicit Association Test (Nesbit 2016) in the USA show that almost $90 \%$ of white Americans display an inherent racialized (positive) bias towards whites. They reflexively and subconsciously associate images of African-Americans with negative (stereotypical) labels and whites with 
positive descriptors. This is supported by research from the National Opinion Research Center at the University of Chicago that shows that "many Americans. .harbour beliefs about racial and ethnic minorities that are based on racial stereotypes" (Nesbit 2016). It is daunting to realize that more than half of the respondents in the survey rated African-Americans as "less intelligent" than whites, and that this included $30 \%$ of the African-Americans answering the survey. In contrast, there are stereotypes about Asian educational performance in the USA. In some research, Asian-Americans were seen in a similar light to Jewish students, specifically in relation to excelling in education while remaining apart from the mainstream as a result of both agency and structural factors (Dhingra 2007: 92), a version of a model-minority stereotype. The latter is an interesting stereotype (how much of it is based on real world educational outcomes as opposed to a simplistic and inaccurate categorization) and it combines negative connotations ("Asian geek" stereotypes) with a begrudging respect.

Stereotypes underpin and contribute to racist categorizations and racialization in a range of ways as the above brief survey indicates. There are also a range of disciplinary emphases, from the role that stereotypes play in social identity theory to the visibility/invisibility of color in different settings. To illustrate the above, a discussion of stereotypes in selected institutional settings is offered.

\section{Stereotypes and Education}

Educational systems are critical in socializing younger members of society and providing a sense of self, of norms, and roles and acceptability. The transfer of knowledge, both formal and informal, is critical but so is an understanding of how individuals or groups are to be characterized and understood. So a central research and policy/political question is whether stereotypes exist and operate in educational institutions, what form they take, and what impact they might have, especially on those targeted.

To explore these dynamics, American research has looked at the presence of stereotypes in young students and the role that these stereotypes play in identity formation. A study of seventh and eighth-grade African Americans tested the degree to which they endorsed race stereotypes or whether self-perceptions would be moderated by what the researchers called "racial centrality" (Racial centrality is the "extent to which race is a central aspect of an individual's determination, and the research question concerns the degree to which an individual identifies with a racial group and the relationship between an individual's self-perceptions and stereotype endorsement). Hence, "for these youth, identity development entails forging an understanding of how race - including the centrality of race for the individual, as well as the meaning ascribed to race by others in the society - is intertwined with personal identity" (Okeke et al. 2009: 2). This draws on earlier research that argued that an awareness of negative stereotypes can negatively impact on the performance of group members, giving rise to stereotype consciousness (McKown and Weinstein 2003). These researchers and others found that both African-American and white 
middle schoolers were more likely to be aware of race stereotypes, in this case relating to academic performance (whites are smarter than African-Americans) than fourth graders. In the case of the Okeke et al. (2009) research, they found that a range of influences and factors were relevant (personality, school characteristics, experiences) and that while causality between stereotypes and self-perception is difficult to establish with cross-sectional data, there remains a concern that some youth are more vulnerable to racial stereotypes.

There is evidence to indicate that stereotypes contribute to educational opportunity outcomes, the education opportunity gap, or educational life chances, from the expectations of key educational players or influential others, and the internalization of these stereotypes for those who are characterized in various and often negative ways. By the time students reach higher education, the education opportunity gap is obvious in advanced economies; although this is played out in different ways depending on which group is the focus. A number of American universities began to operate policies to limit the proportion of Asians in certain programs or institutions - because of what were seen as "educational over-achievement." In this case, stereotypes centered on success (although at times that success was portrayed in negative stereotypes: the Asian "nerd" or "geek" whose only success was educational). Others have focused on the achievement gap that disadvantages AfricanAmerican and sometimes other groups.

Johnson-Ahorlu (2012), rather than describing the educational outcomes gap between African-American and white Americans as an achievement gap, describes it as an "opportunity gap" to highlight the broad nature of educational inequity and to draw attention to the impacts of racism and stereotypes. She examines the "relationship between racism, stereotypes and the ways in which they hinder academic opportunity" (Johnson-Ahorlu 2012: 635), and she does this by moving away from psychological influences and dynamics and uses Critical Race Theory (CRT). This focusses attention on broader societal influences, dominant discourses (in this case, the role of stereotypes), and accepts that the testimonies of African-Americans (here described as "People of Color") are valid in their own right as a source of data and as providing details of the lived realities of the victims of racism and stereotypes. This approach to understanding the role of racism and stereotypes in educational outcomes offers a more critical and politically nuanced approach. This can be seen in her definition of stereotypes, with its focus on structural elements:

Stereotypes can be defined as gross generalizations applied to a group of people with some shared characteristics. In terms of African Americans and other People of Color, stereotypes are often used to justify racism and can provide a rationale for racial oppression and marginalization. (Johnson-Ahorlu 2012: 637)

The effect, Johnson-Ahorlu (2012) argues is that low expectations, especially from university staff, limit career options and majors with the result that AfricanAmerican students experience stereotype threat so that racism was underpinned by stereotypes about educational ability which in turn further contributed to inequitable educational outcomes and opportunities. 
The available research indicates that stereotypes are present in educational settings, although they typically do not originate in these settings but rather the presence and use of stereotypes in an educational institution tends to reflect broader societal influences and origins. The above research provides evidence that stereotypes:

- Play a role in contributing to inter-group educational outcome gaps (or opportunity gaps);

- That they negatively impact on identity and performance and contribute to stereotype consciousness;

- That race stereotypes might be accepted/endorsed by both the hegemonic group and those targeted in stereotypes.

\section{Stereotypes and the Media}

The media have been critical in the perpetuation of stereotypes and sometimes in their creation (see Mastro 2009 for a review). At times, immigrant and ethnic minorities are invisible in the media (which may sustain some stereotypes by omission) but typically, the media have often played a crucial role in using and reinforcing stereotypes. As Fleras and Elliot (1996: 168) argue, "minorities tend to be associated with "race or gender stereotyping" and while there have been improvements in media coverage in recent decades, there is still the tendency to "situate minorities in [the] context of conflict or tragedy," as "problems" in some sense (from being an economic liability to contributing to law and order issues) or as an "adornment," as a form of entertainment in stereotypical roles. This is particularly true when it comes to reporting crime, for example, where public perceptions are often influenced by stereotypes that are reproduced by the media (Giddens 1993: 135). Stereotypes about the association of certain racialized groups and crime has an enduring effect (Hjorth 2017). In this sense, the media can be seen as a "racialized institution in that they reflect (embody) and reinforce a dominant culture's perspective" and that the media (can) "deny or denigrate racialized minorities" (Fleras 2014: 147). The media play a critical role in setting the public and popular agendas.

The recent centrality of debates about immigration provides evidence of the association between often long-standing stereotypes and anti-immigrant views and politics.

The association of restrictionist immigration views ("build the wall!") towards immigrants from Latin America can be directly corelated with negative media coverage of Mexican immigration (Jimenez 2010: 199). Views about the ways in which Mexican immigrants were believed to contribute to the degradation of local communities, the level of cleanliness, or their behavior in public contributed to stereotypes that then characterized the whole Mexican immigrant community negatively. Existing stereotypes were endorsed and expanded by media coverage that in turn encouraged 
media attention and the further use of negative stereotypes to characterize a community, in this case Mexican immigrants. (Jimenez 2010: 200, does point out that there were sympathy among others towards immigrants).

Many of the stereotypes that appear in the media remain, in part or in full, from previous periods. In US popular culture, these historical racial stereotypes in relation to African-Americans include the persona or image of Sambo, Jim Crow, Mammy, Aunt Jemimah, Sapphire, and Jezebell (Green n.d.). Sambo, for example, is a "simple-minded, docile, black man" which dates from a "defense of slavery" that was widely used in the media and which reinforced popular culture (Green n.d.: 3).

Adams-Bass et al. (2014: 368) argue that:

Besides the minstrel-inspired "coons" and "mammies," additional stereotypical characterizations became staple images of Black females ("tragic mulatto"; "sapphire"; "jezebel") and males ("Buck"; "Uncle Tom"...). In spite of social advances, there remains within the TV and film industry a practice of presenting negative stereotype images of Black people scripted from early characters predicated on the racial inferiority of Blacks

They go on to examine how these stereotypes inform and influence adolescent views in the USA towards African-Americans looking at the message transfer between the media and youth. Based on their research, they concluded that there were significant age and gender differences in relation to whether the youth respondents identified the media messages as positive or negative. For example, "males were less likely to identify negative media stereotypes but more likely to endorse the negative messages than females," while younger youth identified more positive media images than older youth (Adams-Bass et al. 2014: 384). Weaver (2011) in discussing Afro-Caribbean comedians in the UK and USA (such as Lenny Henry or Chris Rock) who still employ long-standing racist stereotypes to develop what he calls a reverse semantic effect, or a form of resistance to racist stereotypes. This becomes complicated when a character such as Ali G (Sacha Baron Cohen) is considered, as Weaver (2010) goes on to do. Here there is an inversion of stereotypes, or as Weaver notes, the pretense of a young working class British person from Staines who pretends to a homophobic, sexist, person from an inner-city ghetto in the USA, in this case played by a British Jew who graduated from Cambridge University. It is not unlike other characters such as Alf Garnett in "Til Death Us Do Part" (on British television in the 1960s and 1970s) or Archie Bunker in the American television show "All in the Family" (1970s). Both played racially bigoted individuals and employed a range of stereotypes, both self-directed and at others. There is also the question of how much those targeted by these stereotypes either accept or resist them. One research project (Tukachinsky et al. 2017) examined the effects of television depictions of African-Americans and Latinos on members of the groups. Although the number of African-Americans on US prime time television reached parity with the size (proportion) in the US population, and many of the roles and images had improved, there were still negative portrayals alongside positive ones (Tukachinsky et al. 2017). In comparison, Latinos "are only seen infrequently 
on television - a pattern that has persisted for decades" (Tukachinsky et al. 2017: 3). Their study concluded that "negative media representations ... pose a tangible identity threat to ethnic minorities" and that these "micro-level psychological processes [identity threat] may be occurring on a societal level as well" (Tukachinsky et al. 2017: 19) with concerns that negative stereotyping has implications for wellbeing and health.

These negative images and stereotypes have not gone uncontested. Ethnic minorities, indigenous nations, and immigrants have resisted the negative imaging of them by the media (Fleras 2014). In destination countries such as Canada, Australia, and New Zealand, the immigrant and ethnic minority communities build social capital and ethnic identities (hyphenated and third space identities), and from this base, will seek to confront, challenge and provide alternative readings in the media. Or they might be confronted by particular incidents which help mobilize activism to context negative media commentaries and images (such as the beating of Rodney King in Los Angeles). Immigrant and ethnic organizations and activists seek to develop a "more positive image of their collective membership to confront negative stereotyping in the media" (Simmons 2010: 171).

The role of the media, in all its manifestations (old and new), continues to play a role in perpetuating stereotypes, either by commission or omission. The media landscape in countries like the USA or the UK has changed in recent decades, and there is a greater awareness of the need for sensitivity and self-reflexivity when it comes to issues of diversity, in this case ethnic. There have been some powerful public commentaries and the media commons (see Eddo-Lodge 2017). But equally, the proliferation of media options and the development of media echo chambers have provided new opportunities for racist commentaries and opinions to be shared on a one-to-many basis - and often without disclosing a source or authorship.

\section{Stereotypes and Humor/Satire}

One of the problem areas in terms of the articulation and reproduction of stereotypes is the area of humor: what is permissible and what is not? For example, is it acceptable for someone to use stereotypes when telling jokes when the teller is from the particular group that is being characterized in a stereotypical way? Are there stereotypes that are acceptable (and to whom?). These are problematic issues in relation to the use of stereotypes. It may be that there is recognition that a stereotype is part of a joke but that does not mean that the recipient is in agreement (Hay 2001: 72). As Piskorska (2016: 34) notes, joke stereotypes need to be mutually known to individuals but that might not mean that they are endorsed. So what is mutually known and endorsed (accepted) in contrast to what is not accepted, and indeed, might be regarded as deeply offensive?

There is an interesting literature on the role and acceptability of stereotypes in humor. And it is an area that often draws quite differing responses (this or that ethnic 
group has no sense of humor - it is only a joke!). As Aronson (quoted in Piskorska (2016: 7) notes, a stereotype is most often a set of assumptions about social roles and traits, and Piskorska goes on to explore the stereotypes of Scots as the basis for humor, particularly stereotypes about the perceived meanness (or thriftiness) of Scots. She concludes that such stereotypes rely on being combined with everyday scenarios to give rise to incongruity; they can be augmented to become visibly absurd and given that meanness is an object of ridicule, it supports a sense of superiority (Piskorska 2016: 31). In support of this, Weaver (2011) argues that racist humor acts as racist rhetoric (that is, it can be convincing) which can also impact on nonhumorous discourse (racist truth or truth claims). An embodied racism (that is racism which relies on an earlier biological racism) can reinforce notions of hierarchy and a sense of order (orderbuilding) as part of humor and the reliance on stereotypes.

There are ways of expressing humor and what constitutes acceptable humor. One of the significant moments in these debates occurred with the publication of the Prophet Muhammad cartoons in Denmark in 2015. As Weaver (2011: Chap. 8) argues, the intent and impact of these cartoons are complex, and he suggests that there are four different readings, including as a criticism of Islamic fundamentalism, as blasphemous, as Islamophobic and racist, or as satire which is a defense required in terms of the freedom of speech. He uses the notion of liquid racism to characterize the complexity of the issues in this case. Similarly, comedians such as Ricky Gervais, Jimmy Carr, Frankie Boyle, Dapper Laughs, Daniel Tosh, and Sarah Silverman (Weaver and Morgan 2017) tell jokes that can be seen as a way of challenging prejudice, while others see them as unacceptable and racist/sexist (objectification, devaluation, and violence).

\footnotetext{
Offensive humour is political and highlights a connection between our identities, politics and the pleasure of laughter. When people engage in joking about rape or sexual assault. . .there are intended and unintended consequences for society. In contributing to a blurred distinction between a culture of sexual abuse and humour, rape jokes may contribute to the normalisation of such abuse and make it more difficult that it is already for victims of sexual abuse to speak out. (Weaver and Morgan 2017)
}

Humor often relies on stereotypes - and humorous stereotypes continue to play an important role in popular culture and thinking. But the use of stereotypes as part of comedy or satire, or as part of informal humor in social situations, is highly problematic. Are there stereotypes that are both understood and acceptable? In what circumstances? And does it matter who articulates the stereotypes - and who the audience is. Is it ever acceptable to joke about the Holocaust? Is a joke that relies on a disrespectful stereotype acceptable if the person telling the joke is from the stereotyped community? As Weaver (2011) notes above, even an important example such as the Prophet Muhammad cartoons is open to a range of readings. Often the issue of the use of stereotypes as part of humor is a complex, multidimensional issue. 


\section{Conclusion}

Stereotypes play a key role in racial categorization and the racialization of "other" groups. There are arguments that suggest that stereotypes are part of how humans understand a complex social world, a way of simplifying and making that world understandable. However, stereotypes - as defined here - also involve attributing negative characteristics and behaviors to members of racialized groups, and this contributes to racist world views and discriminatory behavior. Stereotypes contribute to the social control of others and to denigration and/or exclusion. There are real world consequences to the use of stereotypes as part of the presence of racism.

Since the late 1940s, there has been a shift in the acceptability of race as a conceptual underpinning for understanding people and cultures, and the development of both academic and popular understandings that are critical of the presence of racism. This has impacted on some policy and political agendas. However, the recent turn to an exclusive nationalism in countries ranging from the USA to Hungary to Germany has reinvigorated debates about the racism directed towards an "other," and has reintroduced questions about the underpinnings of racism, including the reproduction of often long-standing stereotypes.

\section{References}

Adams-Bass VN, Stevenson HC, Kotzin DS (2014) Measuring the meaning of Black media stereotypes and their relationship to the racial identity, Black history knowledge, and racial socialization of African American youth. J Black Stud 45(5):367-395

Adorno TW, Frenkel-Brunswik E, Levinson DJ, Sanford RN (1950) The authoritarian personality. Harper, New York

Anthias F, Yuval-Davis N (1992) Racialized boundaries. Race, nation, gender, colour and class and the anti-racist struggle. Routledge, London

Awatere D (1984) Māori sovereignty. Broadsheet Publications, Auckland

Banton M (1978) The idea of race. Westview Press, Boulder

Berman G, Paradies Y (2010) Racism disadvantage and multiculturalism: toward effective antiracist praxis. Ethn Racial Stud 13(2):214-232

Castles S, Booth H, Wallace T (1984) Here for good. Western Europe's new ethnic minorities. Plunto Press, London

Dhingra P (2007) Managing multicultural lives. Asian American professionals and the challenge of multiple identities. Stanford University Press, Stanford

Downing J, Husband C (2005) Representing 'race'. Racisms, ethnicities and media. Sage, London

Eddo-Lodge R (2017) Why I'm no longer talking to white people about race. Bloomsbury Circus, London

Fanon F (1967) The wretched of the earth. Penguin, Harmondsworth

Fiske ST (2000) Stereotyping, prejudice, and discrimination at the seam between the centuries: evolution, culture, mind, and brain. Eur J Soc Psychol 30:299-322

Fleras A (1998) Working through differences. The politics of "isms" in Aotearoa. New Zealand Sociology 13(1):62-96

Fleras A (2014) Racism in bicultural Canada. Paradoxes, politics and resistance. Wilfred Laurier University Press, Waterloo

Fleras A, Elliot J (1996) Unequal relations. An introduction to race, ethnic and aboriginal dynamics in Canada (second edition). Prentice Hall, Scarborough 
Freire P (1968) Pedagogy of the oppressed. Seabury Press, New York

Giddens A (1993) Sociology. Polity Press, Oxford

Gilroy P (1987) There ain't no black in the Union Jack. The cultural politics of race and nation. Chicago University Press, Chicago

Goldberg DT (1993) Racist culture. Philosophy and the politics of meaning. Blackwell, Oxford

Green L (n.d.) Stereotypes: negative racial stereotypes and their effect on attitudes towards AfricanAmericans. https://ferris.edu/HTMLS/news/jimcrow/links/essays/vcu.htm. Accessed 17 Sept 2018

Hay J (2001) The pragmatics of humor support. Humor 14(1):55-82

Hjorth F (2017) The influence of local ethnic diversity on group-centric crime attitudes. Br J Polit Sci. https://doi.org/10.1017/S0007123417000424

Hochschild B (2016) Strangers in their own land. The New Press, New York

Hurwitz J, Peffley M, Sniderman P (1997) Racial stereotypes and whites political views of blacks in the context of welfare and crime. Am J Polit Sci 41:30-60

Jewell SK (1993) From mammy to miss America and beyond: cultural images and the shaping of US policy. Routledge, New York

Jimenez TR (2010) Replenished ethnicity. Mexican Americans, immigration and identity. University of California Press, Berkeley

Johnson-Ahorlu RN (2012) The academic opportunity gaps: how racism and stereotypes disrupt the education of African-American undergraduates. Race Ethn Educ 15(5):633-652

Macionis JJ, Plummer K (1998) Sociology. A global introduction. Prentice Hall, New York

Mastro D (2009) Effects of racial and ethnic stereotyping. In: Bryant J, Oliver MB (eds) Media effects. Advances in theory and research. Lawrence Erlbaum, Hillsdale, pp 325-341

McDowell L (2008) On the significance of being white: European migrant workers in the British economy in the 1940s and 2000s. In: Dwyer C, Bressey C (eds) New geographies of race and racism. Ashgate, Aldershot, pp 51-64

McKown C, Weinstein RS (2003) The development and consequences of stereotype consciousness in middle childhood. Child Dev 74:498-515

Miles R (1982) Racism and migrant labour. Routledge and Kegen Paul, London

Miles R (1989) Racism. Routledge, London

Moewaka Barnes A, Taiapa K, Borell B, McCreanor T (2013) Māori experiences and responses to racism in Aotearoa New Zealand. Mai J 2(2):63-77

Murji K, Solomos J (eds) (2005) Racialization. Studies in theory and practice. Oxford University Press, Oxford

Nagel C, Staeheli LA (2008) Integration and the politics of visibility and invisibility in Britain: the case of British Arab activists. In: Dwyer C, Bressey C (eds) New geographies of race and racism. Ashgate, Aldershot, pp 83-94

Nesbit J (2016) America has a big race problem. https://www.usnews.com/news/articles/2016-0328/america-has-a-big-race-problem. Accessed 17 Sept 2018

Okeke NZ, Howard LC, Kurtz-Costes B (2009) Academic race stereotypes, academic self-concept, and racial centrality in African American youth. J Black Psychol 35(3):366-387

Piskorska A (2016) Humour and popular stereotypes of Scots In: Korzeniowska A, Szymańska I (eds) Scottish culture: dialogue and self-expression. Semper, pp 369-379. https://www. researchgate.net/publication/303719570_Humour_and the_Popular_Stereotypes_of_Scots. Accessed 21 Sept

Rex J, Moore R (1967) Race, community and conflict. A study of Spankbrook. Oxford University Press, New York

Simmons AB (2010) Immigration and Canada. Global and transnational perspectives. Global and transnational perspectives. Canadian Scholars Press, Toronto

Spoonley P (1995) Racism and ethnicity. Oxford University Press, Auckland

Tajfel H, Turner JC (1986) The social identity theory of intergroup behaviour. In: Worchel S, Austin WG (eds) Psychology of intergroup relations. Nelson-Hall, Chicago, pp 7-24 
Tukachinsky R, Mastro D, Yarchi M (2017) The effect of prime time television. Ethnic/racial stereotypes on Latino and Black Americans: a longitudinal national level study. J Broadcast Electron Media. https://doi.org/10.1080/08838151.2017.1344669. Accessed 2 Oct 2018

Turner H (1987) Rediscovering the social group: a self-categorization theory. Basil Blackwell, London

UNESCO (1975) Race, science and society. Allen and Unwin, London

Walker R (1990) Ka whawahi tonu matou. Struggle without end. Penguin, Auckland

Weaver S (2010) The 'other' laughs back: humour and resistance in anti-racist comedy. Sociology 44(1):31-48

Weaver S (2011) The rhetoric of racist humour. US, UK and global race joking. Ashgate, Farnham

Weaver S (2013) The rhetoric of racist humour. Routledge, London

Weaver S, Morgan K (2017) What is the point of offensive humour. The Conversation, 10 May. http://theconversation.com/what-is-the-point-of-offensive-humour-76889 